\title{
Photo- and thermo-coupled electrocatalysis in carbon dioxide and methane conversion
}

\author{
Deren Yang ${ }^{1}$, Guoxiong Wang ${ }^{2 *}$ and Xun Wang ${ }^{1 *}$
}

With the large-reserve discovery and exploitation of shale gas and natural gas hydrate all over the world, the production of liquid fuels and basic chemicals by replacing petroleum with abundant shale gas and natural gas hydrate has become the focus of research and development in academia and industry. $\mathrm{CO}_{2}$ and $\mathrm{CH}_{4}$, as the main composition of shale gas and natural gas hydrate, are extremely stable and chemically inert, and thus selective activation and conversion of the two molecules remain grand challenges since the desired high-value products are more reactive than $\mathrm{CO}_{2}$ and $\mathrm{CH}_{4}$. Attributed to anthropogenic activities, billion tons of $\mathrm{CO}_{2}$ and $\mathrm{CH}_{4}$ are directly exhausted per year, and therefore, it is necessary to open up new routes to utilize the small molecular resource (Fig. 1).

Electrocatalysis at mild conditions has been recognized as a promising and alternative route for conversion of $\mathrm{CO}_{2}$ and $\mathrm{CH}_{4}$. However, the electrocatalytic conversion process still suffers from poor selectivity, low reaction rate and insufficient energy conversion efficiency. To overcome the above challenges, external energy input such as solar and thermal energy is expected to promote electrochemical activation of $\mathrm{CO}_{2}$ and $\mathrm{CH}_{4}$, and accelerate the reaction at the electrochemical interface. The key challenges and possible opportunities for photo- and thermocoupled electrocatalysis in $\mathrm{CO}_{2}$ and $\mathrm{CH}_{4}$ conversion are discussed here.

\section{PHOTO-COUPLED ELECTROCATALYSIS IN $\mathrm{CO}_{2} \mathrm{AND} \mathrm{CH}_{4}$ CONVERSION}

Compared with electron utilization above $80 \%$ via electrocatalysis, photocatalysis usually shows much lower photon utilization below 5\%, indicating that most of solar energy is lost (Fig. 2a and b). In the past decade, a series of studies about heterogeneous photocatalysts, photo- catalytic systems and reactor design show a feasible route to convert $\mathrm{CO}_{2}$ and $\mathrm{CH}_{4}$. However, the low yield is still a significant challenge in photocatalysis $[2,3]$. Accordingly, extensive reports propose that external bias input can significantly facilitate the electron-hole separation, and thus photocatalytic activity (Figs $2 c$ and 3a) [4]. Furthermore, a series of studies have reported that the solardriven electrocatalytic $\mathrm{CO}_{2}$ reduction provides a new possibility to meet the above-mentioned challenges in photocatalysis (Fig. 2d). In this system, the photovoltaic (PV) component can convert solar energy directly into electric energy. Meanwhile, the electrochemical cell (EC) accepts the electricity for hydrocarbon and oxygen production. The coupling of the PV and electrocatalytic devices can help us to make more use of solar energy in large-scale application. Although the PV system transforms the solar use-pattern, it does not alter the electrocatalytic nature. Therefore, whether the light field could directly promote the activation and conversion of $\mathrm{CO}_{2}$

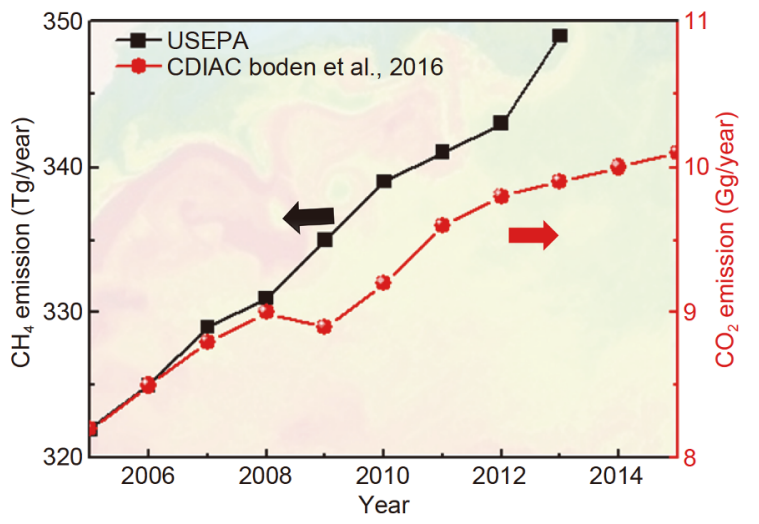

Figure 1 Emissions of $\mathrm{CO}_{2}$ and $\mathrm{CH}_{4}$ from anthropogenic sources. For $\mathrm{CH}_{4}$, emission data (black curve) are plotted from USEPA inventory. For $\mathrm{CO}_{2}$, emission data (red curve) are plotted from CDIAC [1].

\footnotetext{
${ }^{1}$ Key Lab of Organic Optoelectronics and Molecular Engineering, Department of Chemistry, Tsinghua University, Beijing 100084, China

${ }^{2}$ State Key Laboratory of Catalysis, Dalian National Laboratory for Clean Energy, Dalian Institute of Chemical Physics, Chinese Academy of Sciences, Dalian 116023, China

* Corresponding authors (emails: wangxun@mail.tsinghua.edu.cn (Wang X); wanggx@dicp.ac.cn (Wang G))
} 


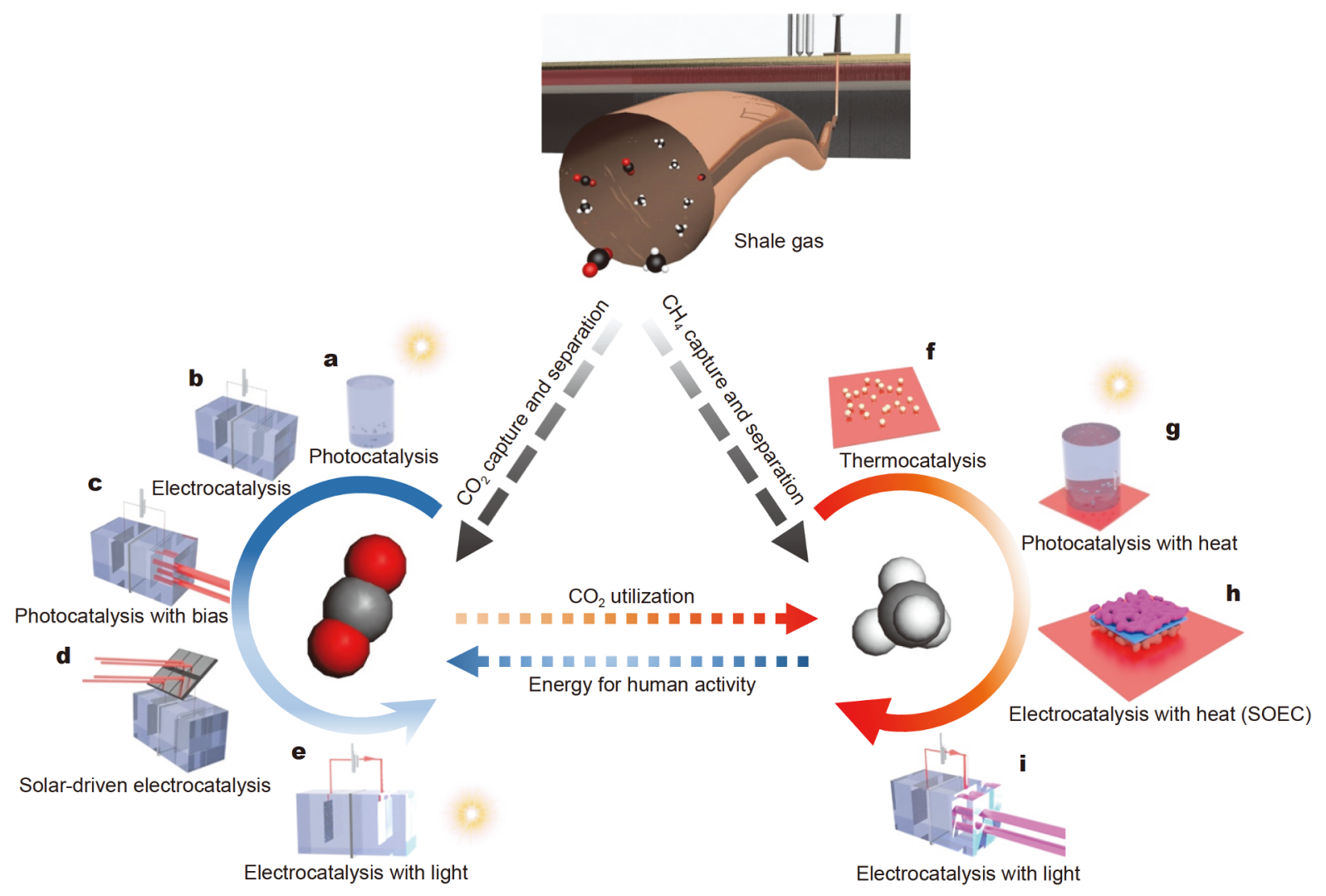

Figure 2 Schematic of photo- and thermo-coupled catalysis in $\mathrm{CO}_{2}$ and $\mathrm{CH}_{4}$ conversion. The schematic shows electrocatalysis, photocatalysis, photoelectrocatalysis and other promising photo/thermo-coupled catalysis in $\mathrm{CO}_{2}$ (left side) and $\mathrm{CH}_{4}$ (right side) conversion.

and $\mathrm{CH}_{4}$ on specific electrocatalysts seems to be neglected but meaningful point.

The central challenge to activate $\mathrm{CO}_{2}$ and $\mathrm{CH}_{4}$ is their low molecular reactivities, which usually require high overpotential or high temperature for initial bond dissociation. When light field is introduced into traditional electrocatalysis, the electronic property of specific electrocatalysts will be easily interfered, such as electron transfer, band-bending, Fermi level and desorption energy of intermediate, and all of these factors will distinctly alter the intrinsic catalytic pathway and performance. Compared with single electrocatalysis, light-coupled electrocatalysis exhibits great potential for small molecules activation at low overpotential with high energy efficiency.

Additionally, the development of photo-coupled electrocatalysts can also play a vital role in this field (Fig. 2e). As previously reported, the catalysts possess two general features, high electrocatalytic activity for $\mathrm{CO}_{2}$ and photosensitized structure. We must stress that it usually consists of three components, including photosensitizer as light harvester, semiconductor as electron mediator and metal component as $\mathrm{CO}_{2}$ activator (Fig. 3b) [5].
Recently, Huang et al. [6] reported a semiconductor/ metal-complex hybrid photoelectrocatalyst. According to this study, light-induced upward band-bending of $\mathrm{Co}_{3} \mathrm{O}_{4} /$ carbon aerogel (CA) lifted the Fermi level, which derived $\mathrm{CO}_{2}$ reduction reaction $\left(\mathrm{CO}_{2} \mathrm{RR}\right)$ at a relatively low onset potential of $-0.45 \mathrm{~V}$ vs. normal hydrogen electrode (NHE), positive shift of $160 \mathrm{mV}$ than thermodynamic redox potential. Another heterostructured electrode was also applied for light-coupled electrochemical reduction of $\mathrm{CO}_{2}$ in 2015 by decorating metallic $\mathrm{Cu}$ nanoparticles on the $\mathrm{Co}_{3} \mathrm{O}_{4}$ nanotube arrays (NTs) [7]. The current transformation efficiency of $\mathrm{Cu}-\mathrm{Co}_{3} \mathrm{O}_{4}$ NTs electrode reaches a maximum of $62.9 \%$ at $-0.89 \mathrm{~V}$ while it increases to $77.5 \%$ at $-0.87 \mathrm{~V}$ under visible light, indicating that light field can assist to lower the electrochemical barrier and promote the electrode kinetics. It is worth mentioning that these hybrid structures not only increase the difficulty of synthesis, but also lower the interior stability.

Therefore, it is urgent to precisely design and synthesize the catalytic structure at the atomic scale, yet there are few reports for us to discuss. Metal-porphyrin and metal-phthalocyanine complexes are used as single-atom 

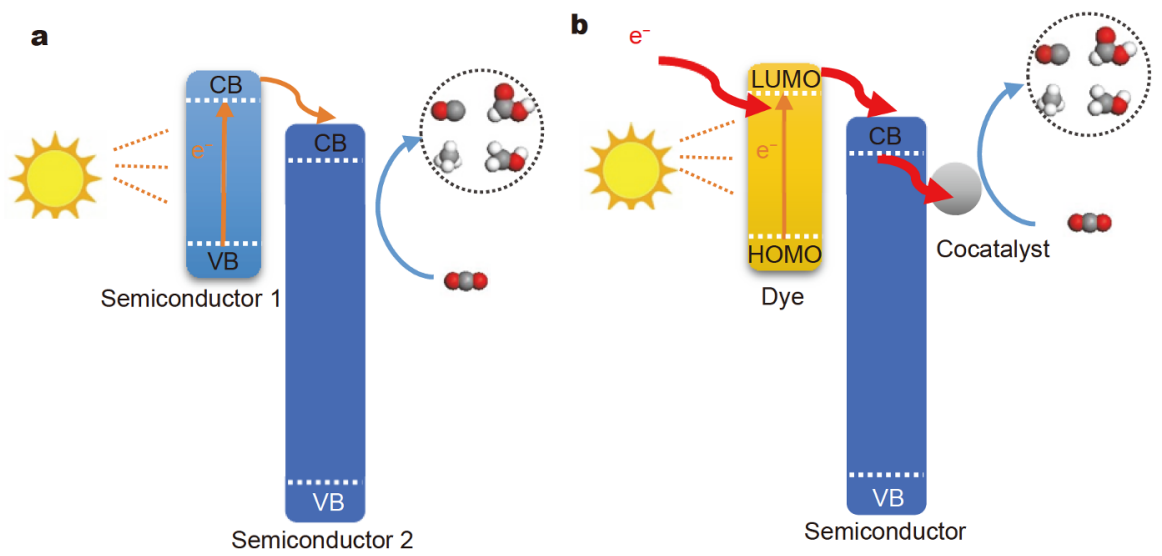
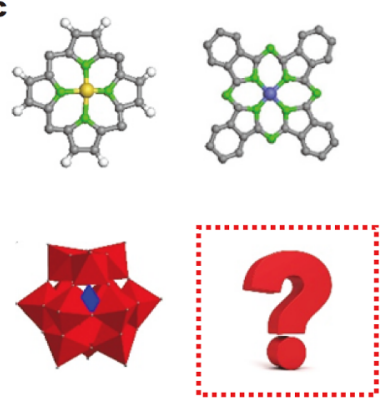

Figure 3 Schematic mechanism for the photoelectrochemical reduction of $\mathrm{CO}_{2}$. (a) Electron transfer on hybrid photocatalyst. (b) CO reduction on photo-coupled electrocatalyst. (c) Promising photo-coupled electrocatalyst, for example, metal-porphyrin, metal-phthalocyanine, metal-polyacid complex and other catalysts.

catalysts in electrocatalysis as well as photosensitizers in photocatalysis, which meet the requirements for "photocoupled electrocatalyst" (Fig. 3c). Furthermore, their electronic performance is susceptible to conjugative perturbation of $18 \pi$ aromatic macrocycle, and hence rational external fine-tuning (light field) may drastically alter the electronic structure of catalytic site. It is expected that more and more well-designed catalysts, such as single atom catalysts, nanocluster catalysts (polyacids) and nanocrystalline catalysts will be designed and applied in this field.

$\mathrm{CH}_{4}$ is another important carbon source consisting of around $90 \%$ shale gas. And the stable symmetrical structure and high $\mathrm{C}-\mathrm{H}$ bond energy $\left(434 \mathrm{~kJ} \mathrm{~mol}^{-1}\right)$ make it difficult to activate at mild temperature, particularly at room temperature (Fig. 2f). Recently, Xie et al. [8] successufully used photoenergy to drive $\mathrm{CH}_{4}$ oxidation reaction on $\mathrm{FeO}_{x} / \mathrm{TiO}_{2}$ at room temperature. Therefore, it is reasonable to anticipate a possible alternative route by employing photoenergy instead of thermal energy, to achieve electrocatalytic conversion of $\mathrm{CH}_{4}$ at low temperature (Fig. 2i). According to previous reports, the $\mathrm{Pt}$ group metals have been used as anode for electrooxidation of $\mathrm{CH}_{4}$ due to their high intrinsic activity. Through integrating atom-, cluster- or nanoparticle-sized Pt-based materials with photosensitive materials (for example, $\mathrm{TiO}_{2}, \mathrm{MoO}_{3}, \mathrm{WO}_{3}$ and $\mathrm{CdS}$ ), a synergistic effect is highly expected to promote $\mathrm{CH}_{4}$ conversion.

\section{THERMO-COUPLED ELECTROCATALYSIS IN $\mathrm{CO}_{2}$ AND $\mathrm{CH}_{4}$ CONVERSION}

Electrochemical oxidation of $\mathrm{CH}_{4}$ has been investigated for several decades, and electro-generated oxygen-con- taining species activate $\mathrm{CH}_{4}$ to produce methanol, ethylene, etc. [9]. However, over-oxidation is difficult to be inhibited and a considerable amount of $\mathrm{CO}_{2}$ is inevitable in the final products. Based on the type of electrolyte materials, the operation temperature of electrolyzer can be varied between room temperature and $850^{\circ} \mathrm{C}$. At a temperature lower than $300^{\circ} \mathrm{C}$, methanol is produced with a considerable selectivity but a poor yield. At $800^{\circ} \mathrm{C}$ or higher temperature, solid oxide electrolysis cell (SOEC) has been investigated to electrochemically convert $\mathrm{CH}_{4}$ into $\mathrm{C}_{2} \mathrm{H}_{4}$ with much increased conversion and selectivity (Fig. 2h) [10,11]. Since the operation temperature of SOEC is similar to that in thermocatalysis, it is possible that both direct electro-oxidation and thermooxidation by electrochemically evolved oxygen at the anode of SOEC would occur simultaneously.

Non-oxidative electrochemical dehydrogenation using SOEC with proton-conducting electrolyte membrane is proposed as a promising strategy to convert $\mathrm{CH}_{4}$ to $\mathrm{C} 2+$ chemicals at intermediate temperature $\left(300-600^{\circ} \mathrm{C}\right)$. At the SOEC anode, the protons are split from $\mathrm{CH}_{4}$ and transport across the electrolyte membrane to generate $\mathrm{H}_{2}$ at the cathode, while the remaining methyl group, either a radical, a cation, or an anion combines together to produce $\mathrm{C} 2+$ chemicals. The separate production of $\mathrm{C} 2+$ chemicals and $\mathrm{H}_{2}$ could increase the conversion efficiency, which simultaneously generate $\mathrm{H}_{2}$ and chemicals. The process would be potentially economical and environmentally friendly.

Electrochemical $\mathrm{CO}_{2}$ reduction reaction pathway is complex, and the product selectivity is low, especially for $\mathrm{C} 2+$ chemicals due to difficult $\mathrm{C}-\mathrm{C}$ coupling. The widelyinvestigated $\mathrm{CO}_{2} \mathrm{RR}$ is in aqueous electrolyte, and major 
advancement has been achieved in recent years. Ethylene with a maximum Faradaic efficiency of $70 \%$ has been obtained over $\mathrm{Cu}$ catalysts [12]; however, the current density and energy efficiency are still required to be greatly improved. At intermediate and high temperatures $\left(450-850^{\circ} \mathrm{C}\right)$, molten salt $\mathrm{CO}_{2}$ capture and electrochemical transformation (MSCC-ET) process has shown promising applications in advanced functional carbon materials [13]. An apparent advantage for MSCC-ET process not only has no poisoning effect of $\mathrm{NO}_{2}$ and $\mathrm{SO}_{2}$ on the electrode catalysts, but also can produce $\mathrm{S} / \mathrm{N}$ doped carbon materials, which show high performance in super-capacitors, lithium ions batteries, fuel cells and catalysis.

SOEC is another promising device for efficient $\mathrm{CO}_{2} \mathrm{RR}$ with several advantages, such as high Faradaic efficiency, current density and energy efficiency. A commercial SOEC system using oxygen-ion conducting yttria-stabilized zirconia (YSZ) as the electrolyte membrane has been demonstrated in 2016 for small-scale and high-purity (99.95\%-99.999\%) CO production by Haldor Topsoe Corp. Recently, using an SOEC with proton conducting electrolyte membrane $\mathrm{BaCe}_{0.7} \mathrm{Zr}_{0.1} \mathrm{Y}_{0.1} \mathrm{Yb}_{0.1} \mathrm{O}_{3-\delta}, \mathrm{CH}_{4}$ was produced with a Faradaic efficiency of $\sim 60 \%$, and the selectivity can be further improved to $\sim 100 \%$ when using a $\mathrm{Ni} / \mathrm{CeO}_{2}$ catalyst to promote the methanation of syngas and $\mathrm{CO}_{2}$ hydrogenation [14].

SOEC also provides a reaction platform to simultaneously convert $\mathrm{CO}_{2}$ and $\mathrm{CH}_{4}$ into chemicals via thermocoupled electrocatalysis, which has been demonstrated in SOEC with oxygen-ion conducting electrolyte membrane. An ideal strategy to convert $\mathrm{CO}_{2}$ and $\mathrm{CH}_{4}$ into high-value $\mathrm{C} 2+$ chemicals is SOEC with proton-conducting electrolyte membrane at intermediate temperatures (300$600^{\circ} \mathrm{C}$ ). However, $\mathrm{CO}_{2}$ is prone to react with the electrolyte materials and decrease the proton conductivity. A feasible way is to decrease $\mathrm{CO}_{2}$ concentration in the fed gas and match the consumption of $\mathrm{CO}_{2}$ during the $\mathrm{CO}_{2}$ $\mathrm{RR}$, which is also of practical significance to eliminate the carbon dioxide enrichment step. The other challenge is to promote the $\mathrm{C}-\mathrm{C}$ coupling and improve the selectivity of $\mathrm{C} 2+$ chemicals derived from $\mathrm{CO}_{2}$ and $\mathrm{CH}_{4}$ conversion while inhibiting carbon deposition. Thus, developing $\mathrm{CO}_{2}$-tolerant proton-conducting electrolyte and highly selective catalysts as well as constructing robust electrochemical interfaces is vital to promote practical applications of SOEC in the near future.

\section{CONCLUSION AND PERSPECTIVE}

The catalytic conversion of $\mathrm{CO}_{2}$ and $\mathrm{CH}_{4}$ requires huge energy input. The electrocatalysis can be powered by renewable electricity, which is abundant and cheap. In order to achieve considerable reaction conversion and rate, electrocatalysis should also be coupled with the photoand thermo-catalysis. The synergistic effect between $\mathrm{CH}_{4} /$ $\mathrm{CO}_{2}$ activation and photo/thermal field is expected to promote a high catalytic performance and make the catalytic conversion more economically viable.

Furthermore, the combination of in situloperando spectroscopy and microscopy techniques, such as X-ray diffraction, X-ray absorption spectroscopy, ambientpressure X-ray photoelectron spectroscopy, etc, and theoretical calculations are urgently needed to provide new insights into the coupling catalytic reaction mechanism. The atomic understanding of photo- and thermo-coupled catalytic conversion of $\mathrm{CO}_{2}$ and $\mathrm{CH}_{4}$ would help to develop active catalytic materials and efficient catalytic processes.

Apart from the fundamental research, many efforts are urgently needed to push forward the potential industrial applications. The scale-up design and assembly of catalytic reactor are vital to demonstrate the advantages of coupling catalysis. The activity and selectivity toward desired products as well as the energy efficiency and durability should simultaneously meet the requirements of industrial applications.

\section{Received 24 May 2019; accepted 6 June 2019;}

published online 27 June 2019

1 Saunois $\mathrm{M}$, Jackson $\mathrm{RB}$, Bousquet $\mathrm{P}$, et al. The growing role of methane in anthropogenic climate change. Environ Res Lett, 2016, 11: 120207

2 Li X, Wen J, Low J, et al. Design and fabrication of semiconductor photocatalyst for photocatalytic reduction of $\mathrm{CO}_{2}$ to solar fuel. Sci China Mater, 2014, 57: 70-100

3 Liu R, Stephani C, Tan KL, et al. Tuning redox potentials of $\mathrm{CO}_{2}$ reduction catalysts for carbon photofixation by $\mathrm{Si}$ nanowires. Sci China Mater, 2015, 58: 515-520

4 Zhang N, Long R, Gao C, et al. Recent progress on advanced design for photoelectrochemical reduction of $\mathrm{CO}_{2}$ to fuels. Sci China Mater, 2018, 61: 771-805

$5 \mathrm{Xu} \mathrm{Y}$, Jia Y, Zhang Y, et al. Photoelectrocatalytic reduction of $\mathrm{CO}_{2}$ to methanol over the multi-functionalized $\mathrm{TiO}_{2}$ photocathodes. Appl Catal B-Environ, 2017, 205: 254-261

6 Huang $\mathrm{X}$, Shen $\mathrm{Q}$, Liu J, et al. A $\mathrm{CO}_{2}$ adsorption-enhanced semiconductor/metal-complex hybrid photoelectrocatalytic interface for efficient formate production. Energy Environ Sci, 2016, 9: 3161-3171

7 Shen Q, Chen Z, Huang X, et al. High-yield and selective photoelectrocatalytic reduction of $\mathrm{CO}_{2}$ to formate by metallic copper decorated $\mathrm{Co}_{3} \mathrm{O}_{4}$ nanotube arrays. Environ Sci Technol, 2015, 49: 5828-5835

8 Xie J, Jin R, Li A, et al. Highly selective oxidation of methane to methanol at ambient conditions by titanium dioxide-supported 
iron species. Nat Catal, 2018, 1: 889-896

9 Xie S, Lin S, Zhang Q, et al. Selective electrocatalytic conversion of methane to fuels and chemicals. J Energy Chem, 2018, 27: 16291636

10 Jiang Y, Yentekakis IV, Vayenas CG. Methane to ethylene with 85 percent yield in a gas recycle electrocatalytic reactor-separator. Science, 1994, 264: 1563-1566

11 Zhu C, Hou S, Hu X, et al. Electrochemical conversion of methane to ethylene in a solid oxide electrolyzer. Nat Commun, 2019, 10: 1173

12 Dinh CT, Burdyny T, Kibria MG, et al. $\mathrm{CO}_{2}$ electroreduction to ethylene via hydroxide-mediated copper catalysis at an abrupt interface. Science, 2018, 360: 783-787

13 Weng W, Tang L, Xiao W. Capture and electro-splitting of $\mathrm{CO}_{2}$ in molten salts. J Energy Chem, 2019, 28: 128-143

14 Duan C, Kee R, Zhu H, et al. Highly efficient reversible protonic ceramic electrochemical cells for power generation and fuel production. Nat Energy, 2019, 4: 230-240

Acknowledgements We gratefully acknowledge the financial support from the National Key R\&D Program of China (2017YFA0700101 and 2016YFA0202801), the National Natural Science Foundation of China (21431003 and 21521091). Wang $G$ thanks the financial support from CAS Youth Innovation Promotion (2015145).

Author contributions Wang X proposed and guided the project. Yang $D$ and Wang $G$ wrote the paper. Wang $X$ and Wang $G$ revised the manuscript. All authors joined the discussion and gave useful suggestions.

Conflict of interest The authors declare that they have no conflict of interest.

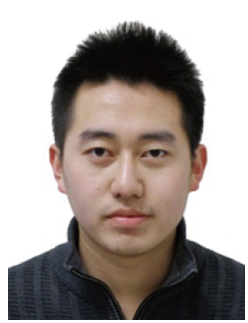

Deren Yang is currently a $\mathrm{PhD}$ candidate in inorganic chemistry under the supervision of Prof. Xun Wang at Tsinghua University. His research interests include the design, synthesis and application of novel catalysts for photocoupled electrocatalysis.

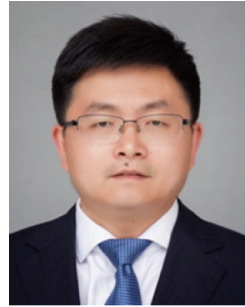

Guoxiong Wang obtained his $\mathrm{PhD}$ in physical chemistry from Dalian Institute of Chemical Physics, Chinese Academy of Sciences in 2006. $\mathrm{He}$ worked at Hokkaido University as postdoctoral researcher from 2007 to 2010. Then he joined Dalian Institute of Chemical Physics in 2010 and became a full professor in 2015. His research interests include highly efficient catalytic materials and processes for electrochemical energy conversion and storage, such as electrocatalytic reduction of $\mathrm{CO}_{2}$, fuel cells and zinc-air

battery, etc.

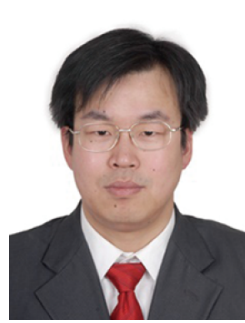

Xun Wang obtained his $\mathrm{PhD}$ in chemistry from Tsinghua University in 2004. Then he joined the Department of Chemistry, Tsinghua University in 2004, and became a full professor in 2007. His research interests include the design, synthesis and application of novel catalysts.

\section{光/热耦合电催化活化二氧化碳和甲烷分子}

杨德仁 ${ }^{1}$, 汪国雄 ${ }^{*}$, 王训 ${ }^{1^{*}}$

摘要 新型催化方法的研究有助于实现二氧化碳和甲烷等小分子 资源的高效利用, 从而优化目前的碳循环工艺. 二氧化碳和甲烷分 子具有较高的键能, 所以它们均为最稳定的分子之一. 在过去十年, 如何实现二氧化碳和甲烷分子的活化一直是世界难题. 传统热催 化通常使用化石燃料作为能源进行小分子活化, 不仅效率低, 同时 会伴随着大量的二氧化碳生成. 最近几年, 一系列具有应用前景的 催化方法逐步被研究验证. 本文不仅系统性地介绍了光/热耦合电 催化在二氧化碳和甲烷等小分子催化转化中的应用, 而且对新型 光/热耦合电催化剂的设计合成进行了展望. 